\title{
A Pluralistic Ecopsychology: Embracing the Tension Between Traditions and Trends
}

\author{
Bradford J. Wiggins, ${ }^{1}$ Dennis C. Wendt, ${ }^{2}$ and Joseph A. Ostenson ${ }^{3}$ \\ ${ }^{1}$ Department of Psychology, Brigham Young University-Idaho, \\ Rexburg, Idaho. \\ ${ }^{2}$ Department of Psychology, University of Michigan, Ann Arbor, \\ Michigan. \\ ${ }^{3}$ Department of Behavioral Sciences, University of Tennessee \\ at Martin, Martin, Tennessee.
}

t seems that, throughout its history, ecopsychology has been perpetually at one "crossroads" or another. In 1995 (during what is sometimes referred to as "first generation" ecopsychology), Joseph Reser asserted that the rise of ecopsychology presented a crossroads to both the discipline of psychology at large and the subdiscipline of environmental psychology in particular. Ultimately, Reser argued that ecopsychology, with its openness to spiritual traditions and commitment to political and social advocacy, was not a "psychology" in the disciplinary sense of the word. In this conclusion he laid out what would largely prove to be the relationship of early ecopsychology to mainstream psychology, with ecopsychology primarily at the margins. A decade and a half later, founding editor of Ecopsychology Thomas Joseph Doherty (2009) called for a revised ecopsychology (aka "second generation") that is more conversant with mainstream psychology while still being true to its countercultural and spiritual roots. Incoming editor Peter Kahn (2013b) has likewise echoed this sentiment, calling for "complementary and synergistic visions" that unite rather than divide a maturing ecopsychology (p. 164). However, Andy Fisher (2013a) has recently argued that this call for reconciliation puts ecopsychology once again at a crossroads. For Fisher, a mainstream STEM-aspiring psychology is diametrically opposed to the lifeblood of ecopsychology; and if the two are to be reconciled, the reconciliation ought to come from ecopsychology helping to liberate mainstream psychology, rather than the former being colonized and co-opted by the latter.

These crossroads, as articulated by both Reser (1995) and Fisher (2013a), suggest that the traditions of ecopsychology and the trends of mainstream psychology are at a sharp divide and that we must choose one or the other (or at the very least transform one to fit the goals of the other). Although we acknowledge that these traditions and trends often contradict and oppose one another, our vision for ecopsychology is one that rejects the either/or of the crossroads metaphor and instead advocates for a pluralism that embraces and maintains the tension between traditions and trends. We see pluralism as particularly important because we believe that no single vision for or articulation of ecopsychology will be adequate. Indeed, such a call for pluralism is not new and in many ways echoes the more contemporary visions of Doherty, Kahn, and others (e.g., Hasbach, 2013; Milton, 2013; Pye, 2013; Sampson, 2013; Sewall, 2013). Nevertheless, we contend that pluralism is much easier to talk about than it is to practice and that achieving a true pluralism demands sophistication, care, and a hearty tolerance for the many tensions pluralism necessarily entails.

A true pluralism is challenging to maintain because it requires a continual tension between the one and the many, between unity and diversity, between sameness and difference. The temptation is often strong to resolve or to sever these tensions that are so crucial to pluralism, as tensions are sometimes messy and uncomfortable. One way this temptation might manifest in the context of this journal could be in compartmentalizing the diverse genres of reports in its pages. Kahn's (2013b) opening editorial, for instance, certainly indicates a commitment to diverse perspectives, inclusive of scientific and poetic accounts, which we applaud. Of course, the demarcation between science and poetics is likely not as simple as it may appear 


\section{WIGGINS ET AL。}

on the surface. For example, many theorists have argued that there is not just one scientific method, but many (e.g., Bishop, 2007; Slife $\mathrm{Ct}$ Williams, 1995), including methods prominent outside mainstream psychology, such as ethnographic and qualitative research designs that embrace narrative and meaning in ways that may begin to approach the poetic. Indeed, Johnson-Pynn and Johnson's (2013) description of their fieldwork in East Africa illustrates the importance of the poetic in such diverse methods. Accordingly, the "beautiful accounts of nature experience" of Kahn's call (2013b, p. 164) do not have to merely be included alongside what are traditionally thought of as scientific accounts; they can themselves be scientific accounts, albeit more likely from qualitative methods that prioritize first-person accounts of human experience. To be sure, there is nothing to say that traditional scientific accounts could not themselves be poetry (e.g., the scientific poetry of Erasmus Darwin, 1791; see Phillips, 2010, for further discussion of scientific poetry, both historical and modern).

The real point with these examples is not only that we ought not to compartmentalize diversity in pluralism but that the tensions within pluralism require that diverse elements engage in meaningful relationship with one another. A true pluralism would require these diverse elements to speak to one another, to challenge and respond to one another, to potentially change one another, and thus would also require a humility that is open to being changed. Such a pluralism may lead us to ask how the literary elements of Ecopsychology might challenge and change empirical elements and vice versa. And although some readers may be able to make meaningful connections between disparate forms of scholarship as they critically reflect on diverse works in this journal, we would argue that it may be necessary to make these connections more explicit through editorials, commentaries, theoretical articles, and alternative empirical articles that may straddle the literary and the scholarly. Thus, a true pluralism should not only foster diversity but also engage diverse elements with one another on the deepest levels possible, which will likely require exploration and innovation on the part of ecopsychologists, as these deep levels may represent uncharted territory.

One example of this sort of exchange is the recent dialogue between Andy Fisher and Peter Kahn (e.g., Fisher, 2013a, 2013b; Kahn, 2013a), debating their diverging visions for ecopsychology. Not only has their debate sparked response and commentary among the ecopsychology community (e.g., Johnson-Pynn \& Johnson, 2013; Pye, 2013), but it has provided a dialectic that embodies these important tensions between the radical and progressive visions of many ecopsychologists. Both Fisher and Kahn challenge one another in ways that likely sharpen their thinking and focus their work, and in making their debate public they invite us to do likewise. Although debates of this sort may sometimes feel like the "infighting and territorial squabbling" that Hasbach (2013, p. 229) wisely warns against, we would argue that, inasmuch as they give voice to the real concerns of ecopsychologists, our disagreements in all of their messiness ultimately serve us as a community and make us better. As Bailey (2013) has argued, we need not be afraid of fierceness in our debates, and we would add that this is particularly the case when we bring with that fierceness a measure of humility and a degree of willingness to be changed by the Other (cf., Milton, 2013).

of course, a particular challenge to such dialogue is the fact that the interlocutors may not always find themselves on an equal playing field, posing the risk that we may unintentionally foreclose on certain perspectives without offering due consideration. We fear there is a tendency for valued and rewarded research activities in mainstream psychology settings to be ipso facto whatever major funders are funding or "high impact" journals are publishing. These influences are understandable for pragmatic reasons, as Hasbach (2013) mentioned. However, if the tension between traditions and trends is to be embraced, mainstream psychologists must remember that alternative research endeavors may be lacking not because of problems with their intellectual or potential empirical merit but because of their not aligning well with the top-down and (often) market-driven priorities of an elite group of decision makers. As qualitative researchers have argued, decisions of what counts for evidence are not adjudicated through a transparent window of reality (as if that were even possible) but are strongly influenced by institutional politics, tribalistic groupthink, and disciplinary tunnel vision (Denzin \& Giardina, 2008). Explicit awareness of this "politics of evidence" is crucial, we would argue, for preserving the tension between traditions and trends. This awareness may at times even call for championing the "underdog" in order to level the playing field as much as may be possible, with care to avoid ultimately dismissing or disadvantaging the mainstream.

Although as ecopsychologists we may each individually favor one path or another in the purported crossroads between the radical and the mainstream, we contend that Ecopsychology (both the journal and the discipline) is best served by a pluralism that looks beyond our individual visions, embracing and preserving the tensions between both paths-trends and traditions. Amid the contradictions and messiness that inevitably accompany the tensions of pluralism, we are optimistic that the growing community of ecopsychologists can bring the sophistication and care a true pluralism demands.

\section{Author Disclosure Statement}

No competing interests exist. 


\section{A PLURALISTIC ECOPSYCHOLOGY}

\section{REFERENCES}

Bailey, C. (2013). Howl. Ecopsychology, 5, 240-241.

Bishop, R. C. (2007). The philosophy of the social sciences. London, England: Continuum.

Darwin, E. (1791). The botanic garden: A poem in two parts (Vol. 1). London, England: J. Johnson.

Denzin, N. K., \&t Giardina, M. D. (Eds.). (2008). Qualitative inquiry and the politics of evidence. Walnut Creek, CA: Left Coast Press.

Doherty, T. J. (2009). A peer reviewed journal for ecopsychology. Ecopsychology, $1,1-7$

Fisher, A. (2013a). Ecopsychology at the crossroads: Contesting the nature of a field. Ecopsychology, 5, 167-176.

Fisher, A. (2013b). Three arguments for a radical ecopsychology. Ecopsychology, 5, 225-227.

Hasbach, P. H. (2013). How deep can we go? Ecopsychology, 5, 228-230.

Johnson-Pynn, J. S., \& Johnson, L. R. (2013). Toward inclusivity, adaptation, and collective action in ecopsychology: Lessons from East Africa. Ecopsychology, 5, 233-236.

Kahn, P. H., Jr. (2013a). Revisioning ecopsychology: Perspectives from the community. Ecopsychology, 5, 207-211.

Kahn, P. H., Jr. (2013b). The next phase for Ecopsychology: Ideas and directions. Ecopsychology, 5, 163-166.

Milton, M. (2013). Eco and queer psychologies: Natural allies to resist "othering." Ecopsychology, 5, 223-224.
Phillips, A. L. (2010). Epic science. American Scientist, 98, doi: 10.1511/2010.86.383. Pye, L. (2013). Diversity at the crossroads: A commentary on "Ecopsychology at the crossroads: Contesting the nature of a field." Ecopsychology, 5, 177-178.

Reser, J. P. (1995). Whither environmental psychology? The transpersonal ecopsychology crossroads. Journal of Environmental Psychology, 15, 235-257.

Sampson, S. D. (2013). Ecopsychology and the third crisis. Ecopsychology, 5, 212-214.

Sewall, L. (2013). Ecopsychology's further emergence. Ecopsychology, 5, 219-220.

Slife, B. D., \& Williams, R. N. (1995). What's behind the research? Discovering hidden assumptions in the behavioral sciences. Thousand Oaks, CA: Sage.

Address correspondence to:

Bradford J. Wiggins

Brigham Young University-Idaho

Department of Psychology

Ricks 110

Rexburg, ID 83460

E-mail: wigginsb@byui.edu

Received: October 16, 2013

Accepted: February 7, 2014 
This article has been cited by:

1. Viney Wayne and Mullen Madisson Department of Psychology, Colorado State University, Fort Collins, Colorado. . 2017. Tempering the Foolish Faiths: William James and Ecology. Ecopsychology 9:1, 26-32. [Abstract] [Full Text HTML] [Full Text PDF] [Full Text PDF with Links] 